\title{
Explore into the Infinite Wonder in Time and Space--On the Pursuit of the Time-Space on an Idea-Sketching Stage in Chinese Opera
}

\author{
Tao Chen ${ }^{1}$ \\ ${ }^{1}$ The Directing Department, The National Academy of Chinese Theatre Arts, China \\ Correspondence: Tao Chen, The Directing Department, The National Academy of Chinese Theatre Arts, No.400 \\ Wanquansi Str. Fengtai District, Beijing, 100073, China.
}

Received: June 18, 2021

doi:10.11114/ijsss.v9i5.5318
Accepted: August 2, $2021 \quad$ Available online: August 6, 2021

URL: https://doi.org/10.11114/ijsss.v9i5.5318

\begin{abstract}
Chinese opera is a highly comprehensive opera that attaches paramount importance to imagery. The qualities of simulative performance, including its orientation, immediacy and flowability, constitutes the transcendent and free time-space of the art of Chinese opera. Considering the profound impact that the spirit of idea-sketching (Xieyi in Chinese, which is an aesthetic conception in China that emphasizes on capturing the spiritual essence rather than the superficial appearance) in Chinese traditional culture has on opera creation, an exploration into the impressionist views in Chinese traditional culture will be necessary to understand the beauty of idea-sketching Chinese opera. The creation of opera directors should be based on the traditional Chinese aesthetics centering on spirit conveying and essence capturing. Opera directors need to explore how the idea-sketching spirit contained in Chinese traditional culture can be applied and extended on the opera stage.
\end{abstract}

Keywords: Chinese opera, idea-sketching, stage, time-space

\section{Introduction}

Chinese opera is a highly comprehensive opera that attaches paramount importance to imagery. The qualities of simulative performance such as orientation, immediacy and flowability constitutes the transcendent and free time-space of the art of Chinese opera. The time-space provided by the stage of opera is free, simulative, and idea-sketching. The principle that "scenery is to be generated by the performers, and is to move as performers move" in the plenty of songs and dances allows the time-space of opera to be dynamic and to demonstrate the dramatic conflict in movement.

The limited space of the stage imposes restrictions on the representation of broader life, but these restrictions can be broken in a creative manner. Opera is "to treat limited time and space of the stage as unfixed, free, and flowing time and space. The stage is lifeless, but in the performance, it can become any place as it has been designated." Through the performance of actors, a stage can be turned into a splendid, inclusive and extensive space. In such a gorgeous space of imagery, the audience get absorbed in the performance of the actors on the stage, making possible a unique experience of artistic enjoyment that arises from a special actor-audience relationship. The imagerized time-space of opera is thus ultimately achieved in the unity of performance on the stage and the resulting imagination of the audience.

\section{Review}

\subsection{Idea-sketching Philosophy in Chinese Traditional Culture}

The idea-sketching spirit has permeated every part of Chinese traditional culture and art. It is an inevitable topic in whatever discussions about the Chinese aesthetics in its traditional culture and art, be it Chinese poetry, paintings, music, dance, sculpture, or traditional opera. The idea-sketching spirit is generalized and refined from Chinese traditional culture and reflects its essence.

"Idea-sketching is not a passive choice of traditional Chinese literati, but an active acknowledgement. The Chinese are so obsessed with the world they have perceived, which is a world full of vigor, that once the 'idea' has been captured and becomes vivid in the heart, it will be a truly perfect and accurate description of the world that is full of vitality by sketching the idea."

In the eyes of the Chinese, "idea" is like an elf wandering across the world. It is elusive, invisible, intangible, and exists at a non-material level. It is in no way the same as "spirit", a concept in Western philosophy. In the words of Chinese philosophy, "idea" 
is embodied in the existence of everything in the world. It is a part of everything. The depiction and simulation of this wandering elf thus facilitates the understanding of the very nature of life in the world. "The literati make use of their life to feel the elf that is wandering across all the things in the world. Then, the 'idea' of the perceiver and the 'idea' of the things becomes one at the moment of perception, and it fills the heart of the perceiver to the extent that he would feel he has to get it out. So, the happiness of unimpeded expression is not only shown in cultural or artistic works that are full of 'idea', but also seen in the expresser himself."

The focus of the culture that tries to describe and simulate the "idea" of everything is naturally put on the concept of "idea". Therefore, in such a culture, the intactness and accuracy of "idea" must be ensured and the objective existence of "idea" must be confirmed.

The idea-sketching culture and art are constructed through depiction and simulation, and expressed when what is perceived gets unleashed. The objectivity of the construction rule and the subjectivity of the expression are inseparable from each other in the idea-sketching culture and art.

In comparison with the representational culture, the figurative art and the expressional culture, abstract art, the idea-sketching culture and art is precisely the specific demonstration of "the beauty of neutralization and harmony".

Idea-sketching is an important feature of Chinese traditional culture and art, especially in contrast to the representational culture and figurative art.

The fundamental characteristic of Chinese art has been decided by the qualities of Chinese culture. The Chinese culture takes a completely different world view from other cultures in that it is a world about Qi. Qi is the foundation of the universe and the very cause for everything to become what it is like now; therefore, it naturally should be the foundation of art works. The formation of Chinese artistic theory from pre-Qin Dynasty to Wei and Jin Dynasties was the same process as the transformation of philosophical Qi theory into artistic Qi theory. From then on, all the art forms have been discussed based on the theory of Qi in China. Qi is intangible. When it is shown in works, it becomes tangible and visible. However, intangibility is still the primary quality of Qi, so the biggest characteristic of Chinese art is its emphasis on the abstract. The coexistence of both the actual and the abstract is a basic norm of Chinese art.

"The artistic state that Chinese ancient literature and art tried to pursue was not reality but ethereality, not similarity in form but echo in soul. That ultimate artistic perfection aspired by generations of litterateurs, the state where you know it is wonderful yet you know not how come it is so, is an objective which can only be achieved based on the refined and implicit artistic expression." And that objective is: Yijing, the artistic state, which has been an important aspect of Chinese aesthetics theory. In the words of Zong Baihua in his A Walk in Aesthetics:

What is the so-called artistic state? When we treat the specificity of our universe and life as the object, appreciate its color, order, and harmony so as to gain an insight into the innermost of ourselves, turn the real into the imaginary, and create a form as its emblem, and make the supreme spirit of mankind concrete in a physical form, we know we are in the desired "artistic state".

As written in the famous "Song of Chi'le" sung in Northern Qi Dynasty, "The plain of Chi'le; North Mount; the dome of heaven; the cover of open grounds; the sky, deep blue; a wilderness unbound; wind blows, grass bends, cattle are seen all around." Just a few strokes are able to sketch a beautiful view of a vast prairie, giving the readers a broad space for imagination and exclamation as infinite charm exudes from these few words. Another example is "Song of Mounting Youzhou Pavilion" written by Chen Zi'ang, "Where are the sages of the past? And those of future years? Sky and earth forever last; lonely, I shed sad tears." This poem conveys a more profound artistic mood. The poet stood at present, looked back at the past and forward into the future, his heart filled with strong emotions. The poem spans a great length of both time and space, able to stimulate unending aftertaste and inexplicable sorrow. The melancholy of bad luck in life, the noble aspiration that cannot be realized, are like spurting out from a volcano, arousing a great empathy from the readers.

This artistic state in Chinse ancient literature is the creation of an image or a kind of mood by integrating subjective feeling and objective environment. It is characterized by picturesque depiction and rich connotations that can inspire the imaginations of the readers with its broad artistic space which transcends any specific images. It is this profound aesthetics spirit of Xieyi that has deeply influenced the opera art of the Chinese.

\subsection{The Time-space of an Idea-sketching Stage in Idea-sketching Art of Chinese Opera}

\subsubsection{Idea-sketching Art of Chinese Opera}

Under the guidance of Chinese traditional aesthetics of idea-sketching, Chinese opera has created a unique paradigmatic beauty. "No resemblance makes no story; too much resemblance makes no art." What the Chinese opera pursues is the very "idea" that stands between "no resemblance" and "too much resemblance".

Wang Jide, a critic of Chinese opera in Ming Dynasty, pointed out that, "The Tao of Chinese opera values the actual in 
its writing but the abstract in its performance." The performance of Chinese opera is supposed to abide by the principle to attach importance to both the actual and the abstract, and simulative performance is the most prominent and most important artistic feature of Chinese opera. The scenery is created through the simulation of the actors and changes as they move. Emotions are integrated in the sceneries, and the idea is conveyed in the images. The objects, sceneries, and emotions created by the simulative performance of the actors together form the artistic state that is inspiring, interesting and charming.

Chinese opera is a kind of art that uses the abstract stage image to simulate the actual life. Simulation is one of the most important features of Chinese opera. "The so-called simulation is to simulate the actual by use of the abstract." With simply some quick steps in a circle, a whip in the air, a pretended horse riding, Chinese opera can show how someone has traveled for hundreds of miles on a horse. Several walk-ons, a couple of maidservants are enough to represent a large troupe or a group of singers and dancers.

It is due to the view of transcendent and free time-space on the stage that Chinese opera can be so adept and flexible in its expression. In the actual performance, it can use lavish details to depict a significant part, or just simple movements to skip any trivial part. The actual can be seen in the abstract, while the abstract is reflected in the actual. A story can be told either at length or in short, with a proper rhythm and a clear focus. Thus, the finite images can be used to represent the infinite world, and the concrete entity can be used to set off imaginations. This kind of simulative expression can be seen everywhere throughout the performance of a Chinese opera.

Simulation, as a unique way to demonstrate how life is like in an artistic way, is never equal to simple repetition and imitation of actual movements in life. Neither is it to create vivid fantasies about life. Chinese opera creatively takes advantage of the fictious nature of art and refines, modifies, beautifies and sublimates the target object in life so that it can be expressed in a concise, distinctive and elegant form to show the inherent nature of human spiritual world and everything in the world. By ingeniously integrating emotions, sceneries, and people together, Chinese opera uses limited images to inspire the audience to make positive associations between the performance and their life, so as to create an imagined reality.

\subsubsection{The Time-space of an Idea-sketching Stage in Traditional Chinese Opera}

The paradigmatic performance in traditional Chinese opera requires its performance space to be empty so that the spirit qualities carried in the paradigm can be expressed to allow the audience immersed in the free transition between the theatre space to the performance space. The specific theatre space in traditional Chinese opera is simulative and assumptive to appeal to the perceptions of the audience. This simulative and assumptive space is mainly created by the movements and performance of the actors on the stage which are regulated by the paradigm that is used to demonstrate the spiritual qualities of categorized characters. Therefore, simulation and assumption are the specific means for paradigmatic performance, and its spiritual carriers as well.

Due to the existence of the contradiction between the infinite life and finite stage, the presentation of theatrical art is greatly restricted in terms of both time and space. The physical space provided by the stage is limited, but the imaginary space created by use of art is unlimited as artists create endless possibilities despite the physical limitations.

The time-space in Chinese opera is free, dynamic, and idea-sketching. It changes with the development of the plot and transforms freely according to the requirement of the specific scenery. It relies on the simulative performance of the actors to achieve the artistic fantasy of "scenery is to be generated by the performers, and is to move as performers move". The play of "Peony Pavilion" has fifty-five acts in total, with dozens of scenery transitions. However, the time-space of the stage is shown with only a table and two chairs, or with a screen in the middle. Simple arrangements of these props are able to show dozens of sceneries of the play. The key to the treatment of the time-space of the stage is human orientation, that is, the time-space of the stage is decided by the performance of the actors. Before the actors put on the performance, the stage is nothing but an abstract space, and it signifies nothing. Once the actors show up on the stage, and with their singing, speaking, acting, and acrobatic fighting, a lively picture of real life comes to the mind of the audience. In this sense, the time-space of the stage is truly created when it involves the participation from the audience.

As the time-space of the stage has to be presented by the actors, the points when the actors get on and off the stage become important indicators of the transition of the time-space and the development of the plot. Every time the actors get on and off the stage, the sceneries get freely changed and the plot can develop naturally.

The presentation of the time-space of the stage should grasp the essential idea and forget the concrete form. The performance-centered theatrical art mainly stresses the performance of the actors. As long as the roles have been properly played, the environment of the stage can be ignored. This is what the saying "What is truly valuable in the performance is people, instead of things." The flexible presentation on the stage breaks free the limited space and saves 
the troubles from setting the stage with real objects. Thus, it rescues the actors from the messy life space and sends them into a theatrical space where they can go beyond the reality to freely play their roles with their songs and dances and express the heartfelt feelings of the characters. With respect to the time-space transition on the stage, Chinese opera focuses even more on grasping the essential idea and forgetting the concrete form. In the Yue Opera "Farewell for Eighteen Miles", Liang Shanbo and Zhu Yingtai went out of "Hang City", "climbed over one mountain after another", before they arrived at "the riverbank" ... The sceneries keep changing, but they are changing on the same stage. All the transitions are enabled by the performance of the actors who sing and act with different movements and expressions in the eyes. In the famous Peking Opera "Search and Rescue of the Orphan", Tu'an Gu said, "I will head for Shouyang Mountain". Then he walked for half a circle on the stage and arrived at Shouyang Mountain from the capital city. The stage stayed unchanged, the table, the chair and the official seal unmoved, yet actor said he was now at Shouyang Mountain. In another Peking Opera "Staying at the Chamber and Killing Yan Poxi", Song Jiang moved from one street to another, from downstairs to upstairs, and then from upstairs to downstairs, as well as the hectic movements after he lost his document envelope - all of the scenery changes were completed on the same small stage.

The focus of the time-space on the stage is always the genuine presentation of emotions by the actors rather than the physical form of the stage. Form is secondary, and can be neglected when it is not needed, or be created by the performance of the actors who use their movements and gestures to stimulate the imagination of the audience in a simulative time-space. And the actors communicate with and respond to each other in this space, and then move again, to express the emotional activities of the characters in specific environments. The setting of the stage is obviously secondary to the depiction of the characters. "Pick up a Jade Bracelet" is not to show the home of Sun Yujiao; "Xu Ce Running through Town" is not to show the bustling streets; "Farewell for Eighteen Miles" is certainly not to show the bridge and river; "Broken Bridge" is not to show the landscape of West Lake... these are familiar examples that have given up the insignificant "form" for the sake of valuable "spirit". Through the paradigmatic performance by the experienced actors, each and every fabulous character of flesh and blood is presented on the stage. And all the performance points to one common goal, that is, to show the "spirit" of the play - the simulative, comprehensive, paradigmatic, and idea-sketching beauty.

\subsection{New Approach to Present the Time-space of an Idea-sketching Stage}

Opera directors in the new age, while inheriting the essences of time-space treatment of an idea-sketching stage, are also making new explorations under the guidance of the principle of the free time-space treatment of the stage.

"The Romance of West Chamber" performed by Zhejiang Xiao Bai Hua Yue Opera Troupe was adapted from a Yuan Zaju Opera with the same name written by the famous playwright Wang Shifu. The entire opera follows the theme of the love story between Zhang Sheng and Cui Yingying, depicting Zhang Sheng as a young man in bold pursuit of his true love and Yingying as an innocent girl yearning for pure love. In terms of time-space transition, the producers of the opera used a turntable which played a significant part in demonstrating the time-space transition and enhancing the expressive force of the emotions of the characters.

Zhang Sheng got lost in love after a single glance at Yingying in a buddha hall. After many ups and downs ("promising marriage", "breaking the promise of marriage", "receiving the love letter" and "replying the love letter"), Zhang Sheng and Yingying finally got together with the help of Hong Niang. In the beautiful moonlight, Yingying, her arm held by Hong Niang, walked up slowly, while Zhang Sheng was waiting anxiously for her. Then a light voice began to sing, "The moonlight pours down over the yard and stairs, and a fairy is walking down the terrace. She is as beautiful as the flower, as delicate as the jade. She walks in hesitation, her heart filled with both fright and love. This is all because of that glance, now a true love that has overcome all the difficulties and waited in patience is ready to bloom." In the melodic vocal accompaniment, Yingying and Zhang Sheng met with each other. In the song, Zhang Sheng, Yingying and Hong Niang moved on the turntable that was slowly rotating, while a group of fairy-like dancers danced around the turntable. With all the dry ice placed under the table, and in the gentle lighting, Zhang Sheng and Yingying held each other in their arms.

In this scene, the director had the turntable rotated counterclockwise not only to indicate the changed environment when the two met with each other, but also to imagerize the progress made in their romantic relationship. While the turntable carried Zhang Sheng and Yingying and rotated on the stage, the dancers were also dancing below the turntable and moved with the turntable. The emotions of the characters got developed and enhanced with the rotation of the turntable, while the audience was also touched deeply with the rotation of the turntable and the dance of the dancers. The emotions of the characters in the play now crystalized as a beautiful image on the stage and got further enhanced with the rotation of the turntable, appealing forcefully to every audience and allowing them to enjoy the utmost beauty of love.

In a lot of other newly created Chinese opera plays, the directors creatively resorted to a range of artistic methods to 
present one after another stunning stage performance. Their treatment that contained rich thoughts and emotions has brought artistic enjoyment to the audience time after time. These new methods take different paths but achieve the same results with the traditional time-space treatment of the stage. Although expressed in different forms, they are still to convey the profound emotions of the characters. Modern directors have also tried to incorporate more in-depth thinking in their innovative expression forms, inspiring the audience to think more.

These excellent treatments of the time-space of the stage did not come purely out of imagination, but were accomplishments the directors achieved by incorporating their opinions on life and using the paradigmatic thought unique to Chinese drama to produce a concise yet profound, philosophical stage deployment after they had fully explored the script, the characters and the historical background of the plot. They come into being thanks to the aesthetics spirit of idea-sketching in traditional Chinese opera, and have the scope of tradition further expanded.

\section{Conclusion}

As the art of traditional Chinese opera has entered a new historical period, opera directors have to meet new requirements. In the creation of modern operas, it is of particular importance for the directors to follow the aesthetic spirit of Chinese opera and use a variety of paradigmatic methods to deal with free, simulative and idea-sketching time-space of the stage. And how to incorporate the principle of time-space treatment of the stage into the creation of modern operas is a new topic for contemporary opera directors to explore.

A number of outstanding opera works inheriting the time-space treatment principle of traditional Chinese opera have appeared on the stage of contemporary opera art. These works not only are marked distinctively with the features of our era ideologically, but also have made certain explorations in the idea-sketching space-time treatment of the Chinese opera as the creators resorted to all possible means on the stage including lighting, sceneries, costumes, etc., to fully utilize the space of stage performance. Following the aesthetic principle of idea-sketching aesthetics in Chinese opera, they have completed one after another wonderful time-space treatment of the stage. These stage treatments, based on the idea-sketching aesthetic spirit of traditional opera, convey more "content" about the creators' understanding of the script, life, and stage based on the traditional paradigms. More information is thus delivered to the audience, who can then have more thoughts while appreciating the beauty of the Chinese opera.

As for the creation of contemporary opera directors, whether it is an adapted costume drama or an opera on modern themes, they should follow the idea-sketching spirit in traditional aesthetics of Chinese opera, deeply study this traditional cultural concept, and use it to understand the script and guide the performance. In the second creation of past works, the directors should focus on exploring the idea-sketching and highly compact time-space of the stage, expand both the depth and breadth of the spatial expression of the stage, and explore more possibilities of performance on the stage.

\section{References}

Hu, Z. F. (2000). On the Second Creation of Traditional Chinese Opera. Beijing: China Theatre Press.

Huang, Z. L. (1990). I and Idea-Sketching View of Theatre. Beijing: China Theatre Press.

Jia, A. (1990). Reexamination of the Law in Chinese Opera Performance. Beijing: China Theatre Press.

Lu, A. (2000). Comparison and Fusion of Eastern and Western Theatre. Shanghai: Shanghai Academy of Social Sciences Press.

Ma, Y. (1988). On the Time and Space of Traditional Chinese Opera. Beijing: China Theatre Press.

Wang, X. Y. (2020). From Hypothesis to Poetic Image. Beijing: China Theatre Press.

Xu, X. Z. (2000). The Directing Art Expanding toward “Expressionistic Aesthetics”. Beijing: China Theatre Press.

Zhang, D. N., \&Fang, K. L. (2004). Introduction to Chinese Culture. Beijing: Beijing Normal University Press.

Zhu, W. X. (2004). Introduction to Chinese Traditional Opera. Beijing: Culture and Art Publishing House.

Zong, B. H. (2015). A Walk in Aesthetics. Shanghai: Shanghai People's Publishing House.

\section{Copyrights}

Copyright for this article is retained by the author(s), with first publication rights granted to the journal.

This is an open-access article distributed under the terms and conditions of the Creative Commons Attribution license which permits unrestricted use, distribution, and reproduction in any medium, provided the original work is properly cited. 